\title{
Seasonal pattern of acute bronchitis in general practice in the United Kingdom 1976-83
}

\author{
JON G AYRES
}

From the Department of Respiratory Medicine, East Birmingham Hospital, Birmingham

ABSTRACT Weekly returns from the Royal College of General Practitioners research unit for acute respiratory illnesses in general practice in the United Kingdom show appreciable variation in attack rates for acute bronchitis, from a peak in January to a trough in August. In 1983, for example, it varied from 171.4 per 100000 to 34.5 per 100000 . This pattern is identical for all years from 1976 to 1983. Attack rates are highest in the extremes of life and lowest in the 15-44 age group. As many cases of asthma are misdiagnosed as acute bronchitis, further analysis of these data will be difficult until the exact diagnostic criteria for acute bronchitis used by these general practitioners are established.

It has been suggested that some if not all children diagnosed as having acute or wheezy bronchitis in fact have asthma. ${ }^{12}$ This may also hold true in adults, where absence of a history of childhood respiratory illness and atopy in a patient who smokes cigarettes is more likely to lead to a diagnosis of acute bronchitis than of asthma. ${ }^{3}$ Acute bronchitis is a condition seen for the most part in general practice and it is responsible for few hospital admissions in a year in England and Wales. ${ }^{4}$

Since 1975 the Royal College of General Practitioners Research Unit has been collecting data from 41 general practices throughout the United Kingdom to assess attack rates for various acute conditions, including asthma, hay fever, and acute bronchitis. These data were used in the present study to detect any trends in acute bronchitis attack rates in general practice in the UK since 1976.

\section{Methods}

Weekly returns are submitted to the Royal College of General Practitioners (RCGP research unit) from 41 general practices throughout the United Kingdom (fig 1), although the number has varied since the start of the service. ${ }^{5}$ The population covered is about 200000 , although slight variations occur from week to week either because the occasional return is not submitted or because of a change in the population

\footnotetext{
Address for reprint requests: Dr JG Ayres, Department of Thoracic
} Medicine, East Birmingham Hospital, Birmingham B9 5ST.

Accepted 11 September 1985 size of an individual practice; this latter factor is small, and the overall population fluctuation is of the order of $5 \%$. The geographical spread of practices reflects the distribution of the whole population of England and Wales - that is, with regard to urban and rural areas; coastal and inland regions; and North, Midlands, and South. One practice is in Scot-

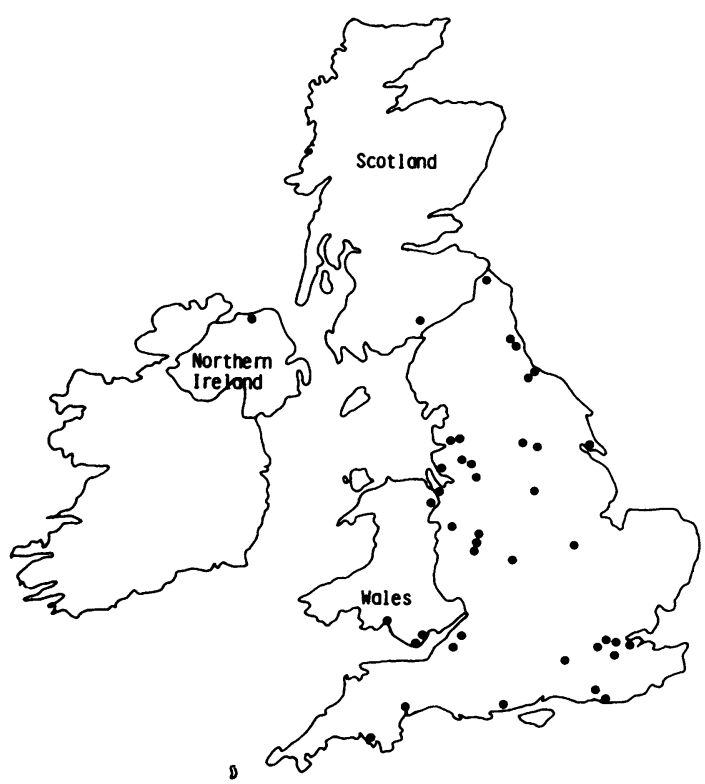

Fig 1 Distribution of the 41 general practices used by the Royal College of General Practitioners in the weekly returns (1983). 
land and one in Northern Ireland. The study population has risen slightly since 1976 (table 1). Each practice has a disease index and uses this in completing the returns. The general practitioner records the number of "events" (for example, attacks of acute bronchitis) seen in that week. Patients are not reentered if they reappear in the surgery at a later stage of the same "event." If, however, they have a second attack that is believed to be quite separate from the first, although relatively close in time, that second attack would be recorded as a new event. The respiratory conditions recorded weekly are listed in table 2 . The list does not include chronic bronchitis (ICD 491) or emphysema (ICD 492) specifically, although space is provided on the return to include these diagnoses as required. Each general practitioner has been shown to be a consistent diagnostician ${ }^{5}$ and, although these data cannot in general be regarded as an accurate source for incidence or prevalence data, they can therefore be used for following trends. The data can reflect only national trends as there are not enough practices to make regional assessment anything other than an assessment of the individual practitioners' diagnostic tendencies, although assessment of areas broadly classified as "North," "Central," and "South" is possible.

The data for acute bronchitis (ICD 466 part) are presented here as (1) weekly attack rates per 100000 population at risk; (2) average weekly rates per 100000 for each of 13 consecutive four weekly periods in each year; (3) average weekly rates per 100000 for each year; and (4) the annual attack rate per 1000 (that is, total number of episodes seen in the year $x$ 1000 divided by the average population at risk). The annual attack rate per 1000 is calculated from the average weekly attack rate per 100000 by multiplying by 0.52 . The same rates are also shown for the age bands $0-4,5-14,15-44,45-64$, and $65+$ for 1983 only.

In the ninth coding revision of the ICD (1978-9)
Table 2 Respiratory disease in the weekly returns*

\begin{tabular}{ll}
\hline $\begin{array}{l}\text { ICD } \\
\text { No }\end{array}$ & Condition \\
\hline $460(\mathrm{pt})$ & Common cold \\
$460(\mathrm{rdr})$ & Influenza like illness \\
$462 / 3$ & Sore throat, tonsillitis \\
461 & Sinusitis (acute) \\
464 & Laryngitis and tracheitis \\
487 & Epidemic influenza \\
$480-486$ & Pneumonia and pneumonitis \\
$466(\mathrm{pt})$ & Acute bronchitis \\
511 & Pleurisy \\
493 & Acute asthmatic attack \\
477 & Hay fever \\
\hline
\end{tabular}

* General practitioners are asked to specify any other recognised respiratory diseases they see during the week.

pt-part only of the ICD number; rdr-remainder.

acute bronchitis has several subheadings (table 3 ). Under the eighth revision asthmatic bronchitis was coded under bronchitis but was transferred to asthma at the ninth revision.

Statistical analysis was by the method proposed by Edwards for cyclic trends, ${ }^{6}$ which analyses trends that conform approximately to a sine wave.

\section{Results}

The attack rates for acute bronchitis (both the weekly and the averaged four weekly rates) show a consistent January-February peak and August trough, a pattern that is nearly identical for all eight years under consideration (fig 2). The trough always occurs in late August at week 34 or 35 (table 1). This cyclical variation is very unlikely to have arisen by chance $(p<$ 0.001). The five fold fall in rates (taking as an example the 1983 figures) from 171.4 per 100000 in early January to 34.5 per 100000 in August is large but could be explained, at least in part, if attendances to GPs for all conditions occurred in a similar fashion. Such a

Table 1 Population at risk and maximum and minimum weekly attack rates per 100000 with weeks of occurrence and the average weekly attack rate per 100000 per annum and annual attack rate per 1000 population per week for acute bronchitis, 1976-83

\begin{tabular}{|c|c|c|c|c|c|}
\hline Year & $\begin{array}{l}\text { Population } \\
\text { at risk }\end{array}$ & $\begin{array}{l}\text { Max weekly } \\
\text { rate (week } \\
\text { of occurrence) }\end{array}$ & $\begin{array}{l}\text { Min weekly } \\
\text { rate (week } \\
\text { of occurrence) }\end{array}$ & $\begin{array}{l}\text { Average weekly } \\
\text { rate }\end{array}$ & Anmual rate \\
\hline $\begin{array}{l}1976 \\
1977 \\
1978\end{array}$ & $\begin{array}{l}189346 \\
171703 \\
164784\end{array}$ & $\begin{array}{l}140.4(8) \\
117.0(53) \\
145.9(5)\end{array}$ & $\begin{array}{c}25.7(35) \\
34.4(35) \\
36.9(34) \\
\text { oding revision }\end{array}$ & $\begin{array}{l}78.7 \\
77.1 \\
90.8\end{array}$ & $\begin{array}{l}40.9 \\
40.1 \\
47.2\end{array}$ \\
\hline $\begin{array}{l}1979 \\
1980 \\
1981 \\
1982 \\
1983\end{array}$ & $\begin{array}{l}175440 \\
202846 \\
196362 \\
195022 \\
204676\end{array}$ & $\begin{array}{l}170.5(1) \\
155.0(1) \\
147.7(6) \\
169.1(6) \\
171.4(1)\end{array}$ & $\begin{array}{l}39.1(34) \\
39.2(34) \\
42.5(35) \\
38.1(35) \\
34.5(35)\end{array}$ & $\begin{array}{r}80.0 \\
84.8 \\
89.0 \\
103.1 \\
91.5\end{array}$ & $\begin{array}{l}41.6 \\
44.1 \\
46.3 \\
53.6 \\
47.6\end{array}$ \\
\hline
\end{tabular}


Table 3 Classification of acute bronchitis in the ninth International Classification of Diseases

\begin{tabular}{lll}
\hline 466 & Acute bronchitis and bronchiolitis \\
& Includes: the listed conditions with or without mention \\
of obstruction or bronchospasm & Excludes: for single condition coding, acute \\
& exacerbation of chronic bronchitis (491) \\
& $\begin{array}{l}\text { Acute bronchitis } \\
\text { Bronchitis, acute or subacute: }\end{array}$ \\
& Fibrinous $\quad$ Viral \\
& Membranous & With tracheitis \\
& Pneumococcal & Croupous bronchitis \\
& Purulent & Tracheobronchitis, acute \\
& Septic & \\
& Acute bronchiolitis & \\
& Bronchiolitis (acute) \\
& Capillary pneumonia \\
\hline
\end{tabular}

fall is seen (fig 3), but it is not large enough to account for the total fall in acute bronchitis rates. In 1983 attendances for all conditions other than acute bronchitis fell by $61 \%$, from 952.7 per 100000 in week 8 to 366.6 per 100000 in week 35 ; whereas the acute bronchitis rates (all ages) fell by $80 \%$. There are obvious falls in attendance rates for all conditions and for respiratory diseases during holiday weeks (fig 3), notably Easter and Christmas weeks, but these are isolated falls lasting just for that week. These falls are also seen in acute bronchitis attack rates.

The crude average weekly attack rate per 100000 per year for acute bronchitis shows a slight upward trend over the last eight years.

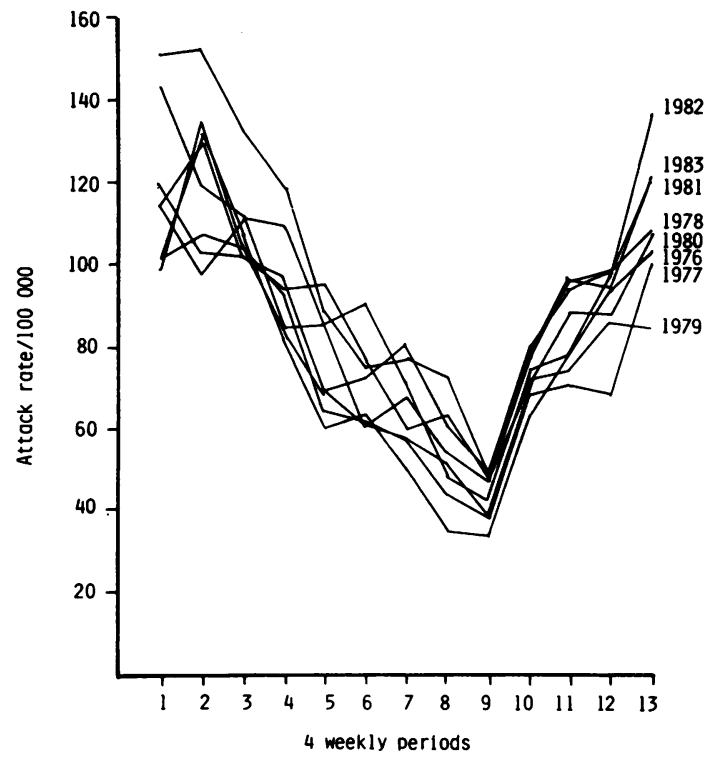

Fig 2 Average weekly attack rates per 100000 for acute bronchitis for each of 13 consecutive four weekly periods (all ages) in each year from 1976 to 1983.
The age specific data for 1983 show that the weekly attack rates (fig 4) are highest in the 0-4 and 65+ age groups.

\section{Discussion}

This source of general practice data has remained largely untapped for respiratory diseases since figures were first collected in late 1975 . The early data, at least for asthma and acute bronchitis, are difficult to interpret because of variation in the size of the population under study (table 1) and because of the important ICD coding revision of 1978-9. Although single events are recorded once only, these data do not allow us to identify individual patients who attend their general practitioner frequently with recurrent attacks. Such patients could confer a significant bias on the result, particularly in conditions with relatively low attack rates; but this is unlikely to be a problem with the high rates seen for acute bronchitis. The data are readily available from the RCGP research unit at Harborne, Birmingham, and age banded data are available from 1982 onwards. The data could be compared with hospital admission data and used for following national trends, although analysis should probably be limited in future to the years following the ICD coding change.

Acute bronchitis is rarely a cause of hospital admission in children ${ }^{4}$ or in adults (Khot, personal communication), and so any study of this ill defined condition must be performed in general practice. Interpretation of the data from the weekly figures is hampered by the lack of definition of acute bronchitis and by diagnostic variability between general practitioners. Nevertheless, some inferences can be drawn from the data.

Firstly, there is appreciable seasonal variation in rates, remarkably consistent from year to year, with a trough in August. This is partly but not completely explained by a fall in attendance for all conditions, and the fall is likely to be real. This seasonal variation in respiratory illnesses has been identified before and may not be totally attributable to season, as temperature and air pollution may contribute. ${ }^{7}$ The fall in attendance during holiday weeks probably owes as much to less ready access to the general practitioner as to any change in disease incidence.

Secondly, acute bronchitis is diagnosed most often in children under the age of 5 , falling to a lower level in the 15-44 age group and rising thereafter. In the older age groups, where chronic bronchitis and emphysema are such common conditions, it is difficult to separate out acute bronchitis pure and simple, especially as there are no separate diagnostic categories for chronic lung disease on the weekly returns. 
Attack rate/

100000

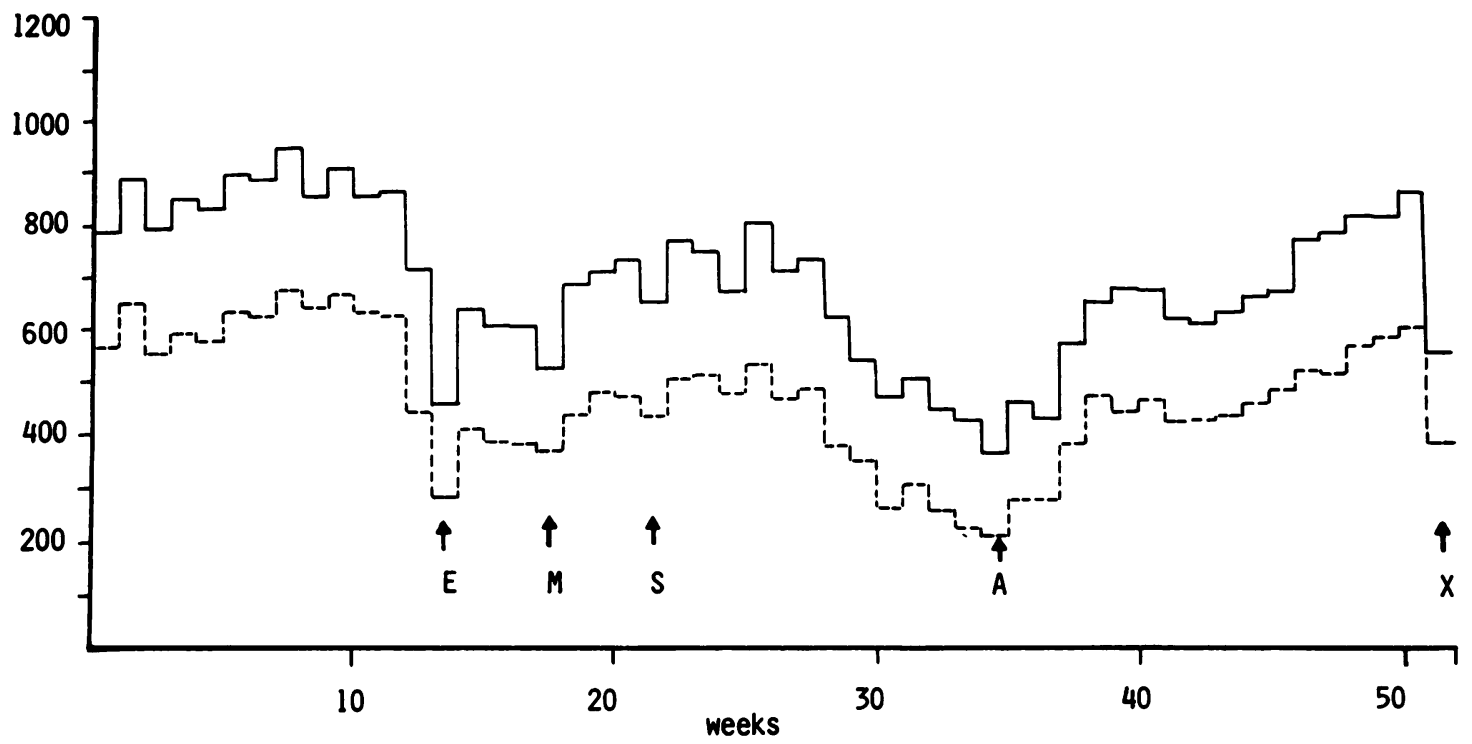

Fig 3 Weekly attack rates per 100000 for all conditions (acute respiratory and infectious diseases) except acute bronchitis, and for total respiratory diseases except acute bronchitis (all ages) for 1983. Holiday periods: E-Easter week; M-May Bank Holiday week; S-Spring Bank Holiday week; A-August Bank Holiday week; X-Christmas week. - All conditions (except acute bronchitis); --- Total respiratory diseases (except acute bronchitis).

In the context of deaths from asthma in children, a similar diagnostic difficulty is separating acute bronchitis and bronchiolitis from acute asthma has led to the belief that the 15-44 age group is less affected by such diagnostic problems. ${ }^{8}$ These data show, however, that the annual attack rate for acute bronchitis in this age group is 28.5 per 1000 per year. If we apply this to the estimated population in the 15-44 age group for 1983 (23.56 million), this represents over 670000 cases a year nationally in this age group. There are bound to be some cases of asthma in this group, and equally some simple, non-recurrent cases of acute viral bronchitis. Viruses are recognised as causing exacerbations of asthma, especially in children in the autumn ${ }^{9}$; and the age banded data above, which give the impression of "mini peaks" in summer and autumn, may mean that such peaks include virus induced asthma attacks. In children, Phelan ${ }^{2}$ has suggested that a diagnosis of "acute bronchitis" may be classified into one of three patterns - an upper respiratory infection with cough (a "chesty cold"), an upper respiratory infection or allergic rhinitis with cough and wheeze ("wheezy bronchitis"), or cough and wheeze without upper respiratory symptoms (sometimes diagnosed as asthma). He goes on to sup- port the contention" that all children with "acute bronchitis" should be regarded and treated as having asthma, as they are more likely to have persistent problems in early adult life. ${ }^{10}$ Acute bronchitis is, however, in reality a "ragbag" diagnosis. Continued use of terms such as "wheezy," "asthmatic," or "spastic" bronchitis will undoubtedly mean that some patients are inappropriately treated with antibiotics instead of bronchodilators. A definition of acute bronchitis in clinical, physiological, and pathological terms is urgently needed for fuller interpretation of these data. Only then can we critically examine the contention that "acute bronchitis is asthma" and study critically the question whether such patients are more likely to progress to chronic airflow obstruction in later life. ${ }^{2}$

I gratefully acknowledge the help and guidance of $\mathrm{Dr}$ DL Crombie, Mrs C Norbury, and the staff of the Royal College of General Practitioners research unit in the compilation of the data for this study. I would like to thank Dr VH Springett for his advice in writing the paper, and Mrs Pamela Jackson for secretarial assistance. 

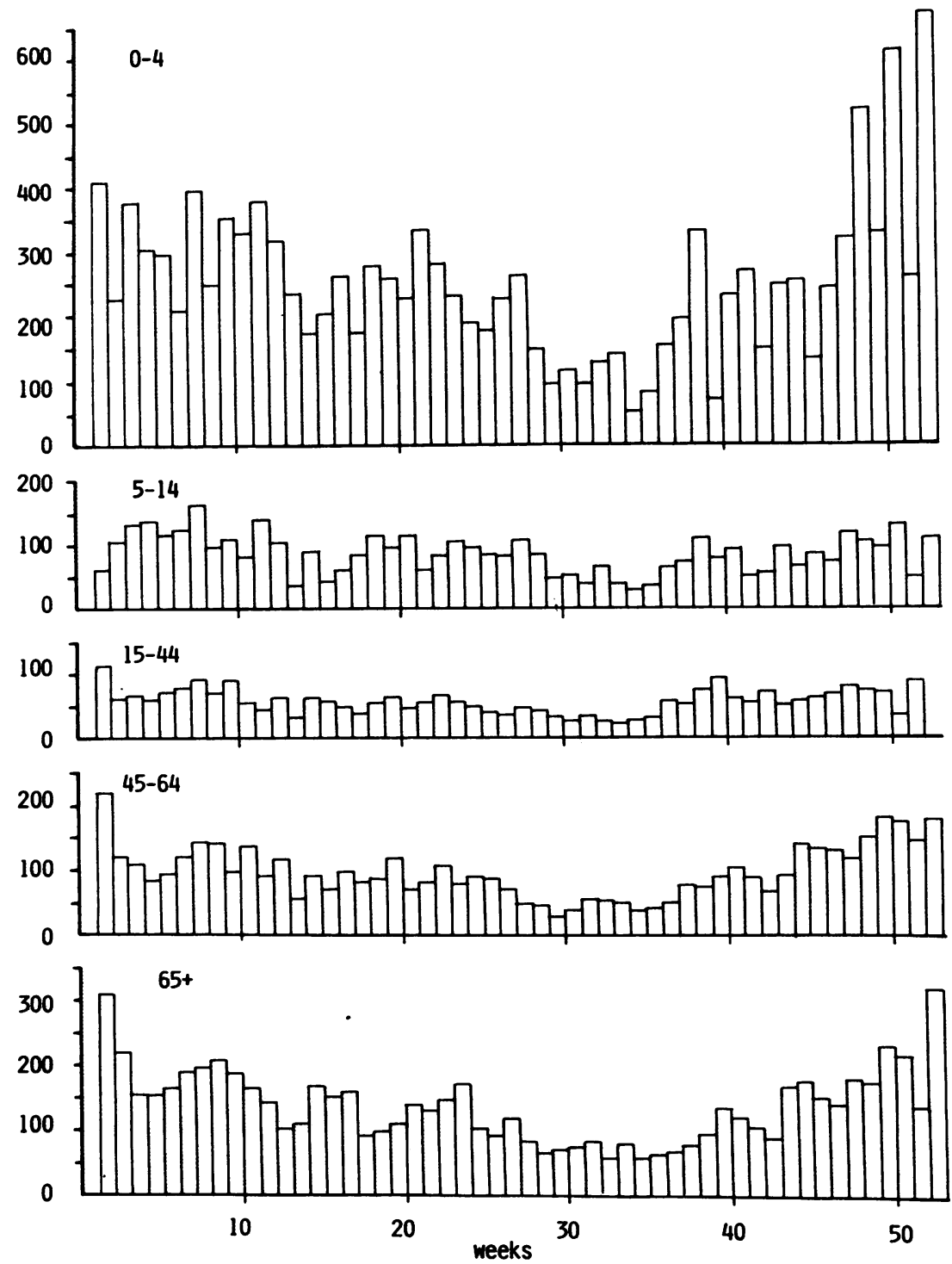

Fig 4 Weekly attack rates per 100000 population, age banded, for acute bronchitis for 1983.

\section{References}

1 Speight ANP, Lee DA, Hey EN. Underdiagnosis and undertreatment of asthma in childhood. $\mathrm{Br}$ Med $J$ 1983;286:1253-6.

2 Phelan PD. Does adult chronic obstructive lung disease really begin in childhood? $\mathrm{Br} J$ Dis Chest 1984;78:1-9.

3 Dodge RR, Burrows B. The prevalence and incidence of asthma and asthma-like symptoms in a general population sample. Am Rev Respir Dis 1980;122:567-75.

4 Khot A, Burn R, Evans N, Lenney C, Lenney W. Seasonal variation and time trends in childhood asthma in England and Wales 1975-81. Br Med J 1984;289:235-7.

5 Fleming DM, Crombie DL. The incidence of common infectious diseases: the Weekly Returns Service of the
Royal College of General Practitioners. Health Trends \% 1985;17:13-6.

6 Edwards JH. The recognition and estimation of cyclic trends. Ann Hum Genet 1961;25:83-7.

7 Holland WW, Spicer CC, Wilson JMG. Influence of the weather on respiratory and heart disease. Lancet $Q$ 1961;ii:338-41.

8 Subcommittee of the British Thoracic Association of Research Commitee. Accuracy of death certificates in bronchial asthma. Thorax 1984;39:505-9.

9 Welliver RC. Upper respiratory infections in asthma. $J$ Allergy Clin Immunol 1983;72:341-6.

10 Martin AJ, Landau LI, Phelan PD. Asthma from child- $\mathbb{D}$ hood at age 21: the patient and his disease. Br Med $J$ 1982;284:380-2. 